\title{
El caminar por la ciudad como práctica artística: desplazamiento físico y rememoración
}

\author{
Gloria LAPEÑA GALLEGO \\ Departamento de Bellas Artes \\ Universidad de Murcia \\ gloria.lapena@um.es
}

Recibido: $12 / 03 / 2014$

Aceptado: 22/04/2014

\section{Resumen $^{1}$}

La acción de caminar por la ciudad es un enfoque que algunos artistas de la segunda mitad del siglo XX han dado a sus creaciones, consiguiendo un doble objetivo. Por una parte, el desplazamiento entre diferentes puntos provocado por la necesidad de acudir al lugar para reconstruir la obra. Y por otro, la rememoración de la historia personal evocada por las sensaciones que despiertan las imágenes encontradas durante el acto de andar. Las herramientas utilizadas para realizar estas obras han evolucionado desde la fotografía y la escritura de los años 60, hasta las nuevas tecnologías y aplicaciones actuales más sofisticadas. Sin embargo, este tipo de propuestas presentan elementos comunes relacionados con la imagen cartográfica de la ciudad como punto de partida para la reflexión de la sociedad.

Palabras clave: City walks, desplazamiento, rememoración, noTours, arte sonoro.

Title: The City Walks and the Memory in the Artistic Practice

\section{Abstract}

The act of walking around the city is an approach that some artists of the second half of the 20th century have given to their creations, getting a dual purpose. On the one hand the moving between different points caused by the need to go to the scene to reconstruct the work. And secondly, the recall of personal history evoked by the feelings aroused by the images found in the act of walking. The tools used to perform these works have evolved from photography and writing of the 60s, to the most sophisticated new technologies and current applications. However, such proposals have common elements related to the cartographic image of the city as a starting point for reflection of society.

Keywords: City walks, moving, remembering, noTours, sound art.

\section{Índice}

1. Introducción

2. Caminar como desplazamiento físico

${ }^{1}$ Este trabajo de investigación forma parte de la Tesis Doctoral financiada con una ayuda predoctoral (19099/FPI/13) con cargo al Programa de Formación del Personal Investigador de la Fundación Séneca, Agencia de Ciencia y Tecnología de la Región de Murcia en el marco del III PCTRM 2011-2014. 
3. Caminar como rememoración

4. Década de los 60

5. Décadas de los 70 y los 80

6. Nuevos enfoques

7. Conclusión

\section{Introducción}

La cartografía de la ciudad y la disposición de su Historia en estratos horizontales constituyen un espacio que puede ser recorrido con el fin de recuperar las huellas del pasado. En este caminar queda anulada la línea del tiempo para entremezclar vivencias en redes dominadas por la anacronía espontánea y guiada por la experiencia. Se reconstruye, de este modo, la historia personal, la de los sentimientos y las emociones que se apropian del escenario, espacio por el que se transita. Los elementos actuales de la ciudad se mezclan con otros desaparecidos que se reinterpretan a través de imágenes. Ya no importa la Historia encorsetada en fechas y hechos, sino la historia como experiencia de quien recorre los espacios que persisten en el mapa trazado por unos antepasados, y de los que podemos imaginar nuestra historia personal. El acto del caminar nos hace pensar y construir un mundo propio que oscila entre lo real y lo imaginado (Rubio Remiro 2011). Este balanceo propuesto supone el pendular entre la Historia y nuestra historia, o un pasado vivido por otros y nuestro pasado, que es presente y futuro. Se sitúa más en el plano metafórico del caminar en el tiempo que a través del espacio, en consonancia con Jacques Lacarrière: "Al caminar lo que cambia es el tiempo, no el espacio. Y ello se comprende porque no puede haber un verdadero viaje sino en el corazón de este espacio de tiempo encontrado" (Lacarrière apud Rubio Remiro 2011: 21).

En el plano artístico, la acción de caminar por la ciudad ha servido para reconstruir la historia de lo cotidiano, lo paralelo, aunque no independiente, al acontecimiento histórico. Las obras derivadas de este enfoque presentan una estética diferente según las herramientas y tendencias del momento en que son creadas. Sin embargo mantienen el punto de encuentro del doble caminar en el que se implican dos tipos de acción:

Una, fácilmente comprensible, la del recorrido que todos entendemos como desplazamiento físico. Dentro del espacio, la distancia es una longitud que une un inicio con un fin. El modo de unir ambos no es otro que el de situarnos, por nuestros propios medios o ayudados, en cada uno de los infinitos puntos que dibujan la línea imaginaria trazada entre la salida y la meta. La exigencia de recoger sensaciones en distintos lugares del espacio, para reelaborar la obra, se convierte en práctica artística del participante. 
El otro tipo de acción resulta más complejo. Es el caminar temporal, puramente metafórico, alejado de los dictados de la Física o de la Historia, y puede realizarse in situ por medio de la mente como una de las categorías de viajes hacia la memoria histórica (García y Rubio 2010). La complejidad se debe fundamentalmente a la percepción que podamos tener frente al concepto de pasear por el tiempo. No obstante, no es importante la compresión de las bases físicas del movimiento temporal, puesto que es un carácter innato e inherente al individuo. En este sentido, los artistas no pretenden fijar fechas determinadas con el fin de realizar investigaciones historicistas, sino que los hechos personales o de la sociedad que se encuadra en una ciudad concreta sean simplemente el punto de partida y de reflexión para el público al que va dirigido.

Con el fin de analizar estos dos tipos de acciones en obras sobre el caminar, seleccionamos una serie de artistas cuyas creaciones se adaptan al desplazamiento por la ciudad. El principal objetivo de este estudio es relacionar su producción con los recorridos espacial y temporal como punto de encuentro, y analizar la evolución cronológica con arreglo a la introducción de nuevas tecnologías en el mundo del arte. Para una mejor exposición y comprensión de nuestra hipótesis de trabajo, separamos los dos tipos de caminar propuestos, si bien esta independencia no es real y ambas se contaminan mutuamente por la interrelación entre espacio y tiempo. A continuación, expondremos las características de artistas que han abordado el concepto de caminar por la ciudad mediante diferentes técnicas. Por último, concluiremos con un estudio de los elementos comunes en este tipo de intervenciones.

\section{Caminar como desplazamiento físico}

Se ha reflexionado y escrito mucho acerca de cómo las ciudades, desde hace ya unos cuantos años, han dejado de ser un lugar estable para convertirse en espacios en los que la movilidad y el tránsito son dos de sus rasgos más significativos. En la mayoría de los casos esta situación es analizada como un problema, ya que se trata de un "desplazamiento sedentario" en el que no es nuestro cuerpo lo que se mueve físicamente, sino un aparato artificial externo, como puede ser, por ejemplo, la televisión, que nos lleva en un instante a cualquier rincón del mundo desde nuestro sofá; o el coche, que es en realidad un sofá con cuatro ruedas. Velocidad del medio e inercia del cuerpo es la verdadera situación que estamos viviendo. Con el objetivo de minimizar el tiempo de estos desplazamientos, se han generalizado las redes de infraestructuras comunicativas ligadas al aumento de circulación de vehículos e información y se han adoptado fórmulas y criterios de orientación, como señales que nos indican cómo debemos desplazarnos y mapas que nos señalan únicamente los lugares que, al parecer, merece la pena visitar. Por el contrario, el 
paseante goza de la libertad espontánea y elige el lugar familiar hacia dónde dirigirse por sus propios pasos para disfrutar a través de la mirada (Gawoll 1994).

El acto de arrojarse a las calles y dejarse llevar era su lucha particular contra el aburrimiento. Entregarse a un desconocido (el Otro por antonomasia) conllevaba adentrarse en una aventura, romper con las dinámicas cotidianas de una sociedad presidida por el automatismo. La certeza de no saber hacia dónde conducen los pasos convierte el paseo en una deriva. La palabra deriva es utilizada por primera vez por Gilles Ivain en 1953. El primer referente lo encontramos en la visita dadaísta, cuyos participantes simplemente se limitaron a fotografiarse para dejar constancia de su llegada al lugar. En mayo de 1924, Louis Aragon, André Breton, Max Morise y Roger Vitrac realizaron la primera deambulación surrealista 0 recorrido sin destino (Careri 2002). A diferencia de las deambulaciones dadaístas, los surrealistas caminaban campo a través, con una intención de retorno a lo primitivo, a la esencia de la desorientación y el abandono al inconsciente.

En 1956, en respuesta al deambular azaroso de los surrealistas, Guy Debord, fundador de la Internacional Letrista, elaboró la Teoría de la deriva, encaminada a la creación de una ciencia: la Psicogeografía, que definía como el ejercicio de deambular metódico en diferentes ambientes en la ciudad en busca de nuevas experiencias para su localización y descripción (López Rodríguez 2005: 79-89). La palanca de acción era la construcción de situaciones, de donde la Internacional Situacionista tomó su nombre. El procedimiento consistía en la creación de desplazamientos transitorios de carácter urbano e industrial, desde los que el individuo vivía una aventura a través la vida diaria.

\section{Caminar como rememoración}

Walter Benjamin es quizás el filósofo y crítico literario por excelencia que ha estudiado el concepto de viaje a través del recuerdo. Para Benjamin, el proceso no tiene nada que ver con la mnemónica, y se asemeja a una excavación continua para acercarnos a nuestro propio pasado sepultado (Benjamin 1992). La memoria involuntaria o subjetiva, contraria a la memorización totalmente objetiva, resulta más enriquecedora. Cada uno escribe su propio libro interior, predominando la profundidad y lo sustancial sobre lo superficial y las apariencias (Sánchez Ruiz y López-Aparicio 2008). Sobre esta reflexión se insiste en diferentes libros como Sobre algunos temas en Baudelaire (1939) de Benjamin y Materia y memoria (Bergson 1959). Se erige una nueva manera de entender la sensibilidad más allá del control consciente y subjetivo de la sociedad del siglo XX. Hablamos de objetos concretos, palabras recordadas, aromas y ruidos, para hacer frente a la objetividad y esforzarse en escuchar las cosas 
insignificantes que no deben darse por perdidas en la historia porque el tiempo dé pistas falsas sobre la verdad (Pinilla Burgos 2010).

En un pasaje de Walter Benjamin sobre sus recuerdos en París, habla de los objetos, las calles, el asfalto, en definitiva, lo no humano que le enseña su lenguaje único. En esa soledad es cuando las relaciones con los seres humanos alcanzan profundidad, "pues es esencial a toda cosa comunicar su propio contenido espiritual" (Benjamin 1970: 145). Por otra parte, utiliza la imagen cartográfica de la ciudad cuando en 1932 escribe por primera vez sobre sí mismo de una manera subjetiva. Se trata de Crónica de Berlín, una obra inacabada que supuso un taller de recuerdos de un largo periodo de su infancia o un proyecto de escritura pública con el fin de recordar. En esta obra articuló su vida en un mapa militar de la ciudad de Berlín, anticipando esta ciudad como escenario de guerra, quizás una premonición. El color gris de aquel mapa militar sería el fondo para colocar colores de los lugares importantes, un "espacio de vida". La Berlín vivida por Benjamin tiene relación con su admiración por Marcel Proust y la concepción de lo auténtico en lo ínfimo (Pinilla Burgos 2010).

Esta forma de entender el caminar por la ciudad tiene su antecedente en la figura literaria parisina del flâneur, cuyas observaciones llevan intrínseco un carácter de extrañamiento ante el espectáculo de la ciudad. Sus visiones parecen denunciar una especie de aburrimiento urbano que se apodera de los ciudadanos, la pérdida de la identidad entre la aglomeración y la sumisión a las distracciones que ofrece el espectáculo urbano. Adquieren un sentido mucho más crítico, que supera la observación, a priori pasiva, del flâneur, para fundamentar un cuestionamiento crítico de las matrices y códigos cotidianos. Las obras basadas en la acción de caminar por la ciudad, como veremos, han heredado las intuiciones que se plantease Benjamin, adaptándolas a la problemática actual.

\section{Década de los 60}

Los artistas que a partir de los años 60 experimentan sus obras dentro del city walks buscan a través de las imágenes y las sensaciones sus propios recuerdos. Tienen su base teórica en los trabajos de Benjamin. Robert Smithson (Nueva Jersey, 1938-1973) realizó en 1967 una obra consistente en fotografiar objetos y arquitecturas industriales abandonadas de su barrio natal Passaic (Nueva Jersey), mientras viajaba en autobús y a pie. A partir de esa experiencia, Smithson publicó un artículo en Artforum (diciembre de 1967), inauguró una exposición con 24 fotografías de los "monumentos" fotografiados y su localización en un mapa en negativo e invitó al espectador "a recorrer junto al autor-descubridorguía el Passaic River", con el fin de explorar "una tierra que ha olvidado el tiempo" (Careri 2002: 160). Su obra es el conjunto de 
fotografías expuestas (figuras 1 y 2), las que disparan los visitantes, el hecho de haber realizado un recorrido y de invitar a otras personas a caminar por Passaic River y la publicación en Artforum. "La obra es todas esas cosas a un mismo tiempo" (Careri 2002: 162).
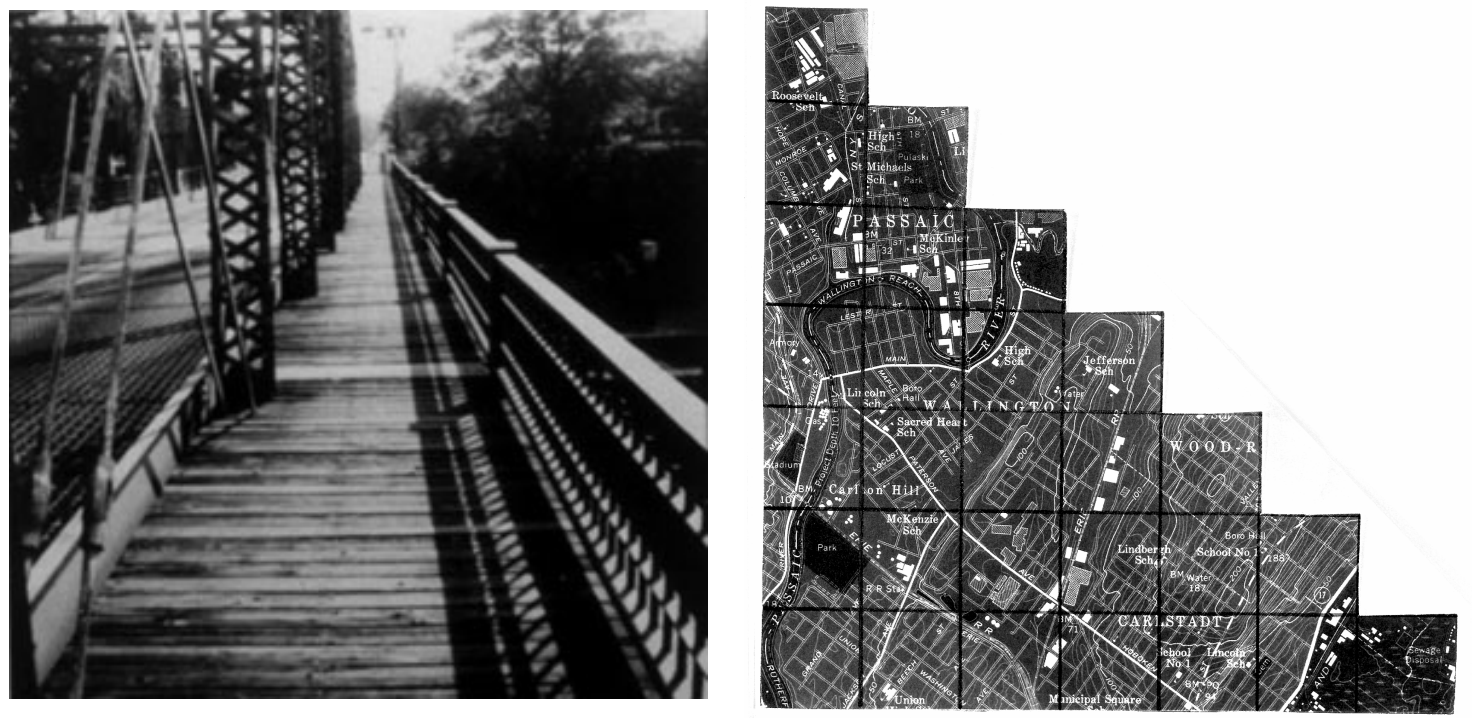

Figuras 1 y 2. Imágenes del libro de Robert Smithson Monuments of Passaic (1967: 12 y 24) en el que nos presenta los nuevos monumentos de la periferia contemporánea. Izquierda: "El monumento puente mostrando las aceras de madera". Derecha: "Mapa en negativo que muestra la región de monumentos a lo largo del río Passaic".

Las teorías que se centran en la representación del recuerdo planteadas por Marrot (2006) a partir del análisis de cuatro obras entre las que se encuentra la de Robert Smithson, se refieren a la memoria individual o autobiográfica, relacionada con la identidad personal. Mira las cosas de un modo distinto al de un mero inventario (Cruz 2007), para generar un producto elaborado por nosotros mismos a partir de materiales preexistentes y de acuerdo con unas determinadas reglas (Halbwachs 1968). Según Giorgio Agamben (2007), el presente individual se recompone a partir del pasado, creando una imagen dialéctica que no existió en el pasado, pero que enfrenta pasado y presente. Surge así el carácter creativo de la memoria involuntaria por el grado de reflexión del sujeto implicado (Oberti y Pittaluga 2006).

El Berlín de Benjamin en su Crónica de Berlín y el barrio natal de Smithson en Passaic River suponen para ambos un lugar para la evocación de recuerdos de su infancia y juventud. Caminan por su ciudad y buscan lo que queda, el objeto o la reliquia, diferente ahora a cómo lo recuerdan, pero suficiente para traer un pasado al presente situado en un mapa personalizado. En cierto modo, suponen un intento de recuperar unos restos arqueológicos sepultados y situarlos 
en un mapa actual superpuesto. La utilización del mapa se impone como guía necesario para el acto de caminar. De Diego (2008) lo define como "la descripción del mundo", y no tiene por qué ser totalmente objetivo en cuanto a los espacios establecidos, sino que puede dibujarse en términos de poder o de definición del mundo. Incluso, aunque podría parecer la forma más natural de representar un mapa geográfico desde la mirada de un extraterrestre, la fijación de los lugares va ligada al viaje. "En definitiva, el mapa geográfico, si bien es estático, presupone una idea narrativa, está concebido como un itinerario, es una odisea" (Calvino apud Careri 2002: 152).

En el mismo sentido, los situacionistas apuestan por un arte en relación directa con la vida de la ciudad, en un pasado más reciente. Realizan mapas psicogeográficos en los que establecen relaciones que tienen que ver con las emociones suscitadas por los distintos ambientes urbanos, no con la funcionalidad de los mismos. El origen de estos mapas estuvo influido por el ensayo sociológico parisino de Henry Chombart de Lauwe (1965), titulado Paris et l'agglomération parisienne. En él se incluía un mapa de seguimiento que recogía el trayecto realizado en el año 1950 por una estudiante parisina. Sus movimientos dibujaban la figura de un triángulo en cuyos vértices estaba su casa, la de su profesora de piano y la Escuela de Ciencias Políticas.

\section{Décadas de los 70 y 80}

La seguridad que tenía Robert Smithson sobre los lugares por los que debía caminar puede desfigurarse hacia un estado constante de desorientación e incertidumbre en el que el ciudadano siente cómo todo lo que le rodea pierde su propia cualidad material y adopta un carácter provisional. Esta sensación es la que debió experimentar la artista conceptual Sophie Calle cuando, en 1979, regresó a París tras un largo viaje de siete años por buena parte del mundo. Se sentía perdida en su ciudad natal, sin saber hacia dónde dirigirse, de modo que comenzó a llevar a cabo una serie de "rituales" de exploración y reconocimiento que consistían en seguir a determinadas personas que encontraba en la calle, dejando que fueran otros quienes decidieran por ella su camino. A partir de ese momento, cuenta su biografía en primera persona directamente a través de confesiones sobre su pasado o bien de manera indirecta mediante narraciones de las experiencias que vive durante sus desplazamientos.

La personalidad de la artista y algunos datos de su vida sirven a Auster (1992) como reflejo del personaje María Turner de la novela Leviatán. El género que utiliza en su obra es en todo momento la autobiografía, rompiendo las fronteras entre el arte y la vida, lo público y lo privado. Heredera de la tradición situacionista, la mayoría de sus trabajos parten de la construcción de situaciones basadas en desplazamientos por la ciudad sin un itinerario prefijado, abierto ante 
cualquier forma de encuentro que le permita adentrarse en nuevas experiencias. Realiza una labor activa de búsqueda e indagación en la que la artista analiza sus experiencias y las traduce en una obra artística en forma de narración en la que ella misma es el personaje protagonista. De esta manera, la introspección se convierte en extroversión.

Formalmente, Sophie Calle se expresa a través de una multiplicidad de medios: fotografía, texto, vídeo, libros, folletines en periódicos e instalaciones. Una característica común es la combinación de texto e imagen. En cuanto al texto, el estilo se podría calificar de narrativo: las cartas y los diarios son frecuentemente elementos clave y se inspira a menudo en la literatura, el periódico o la foto-novela. Concede una gran importancia al detalle y el menor acontecimiento cotidiano (una agenda encontrada en la calle, la desaparición de una joven o una carta de amor) puede desencadenar el deseo de hacer una obra de arte. Las fotografías de sus primeros trabajos, en blanco y negro y de distintos formatos según la pieza, están lejos de lo que es entonces considerado museístico, sobre todo en los primeros proyectos, y remiten siempre a pruebas, testimonios. Con el tiempo, sus imágenes comenzarán a adoptar un sentido estético, otorgando importancia al mundo de las emociones.

La intromisión de la artista en la vida privada de extraños se ha llegado a identificar con la actitud del voyeur que se complace del poder de su mirada sobre aquellos a los que observa desde un lugar privilegiado. Sin embargo, en un artículo para la revista Acento, "Los rostros olvidados: Sophie Calle o la flâneuse contemporánea", Martina Deren (2010) rechaza esta comparación y señala la actitud productora de la artista (contraria a la del badaud o mirón) con objeto de presentarla como una nueva tipología de flâneuse de la actualidad, reinterpretada a través de Benjamin (2004), según el cual para el flâneur, su ciudad, aunque haya nacido en ella, no es ya su patria, sino más bien un escenario. Sophie Calle encarnaría este nuevo modelo de flâneur que ya no reconoce su París y que de manera espontánea comienza a moverse a merced de otros. Durante el camino, anota minuciosamente en su libreta todos los movimientos de los desconocidos y les toma fotografías. Su intención no es la de establecer algún tipo de relación con ellos; todo se limita a una labor objetiva de documentación desde el anonimato. 


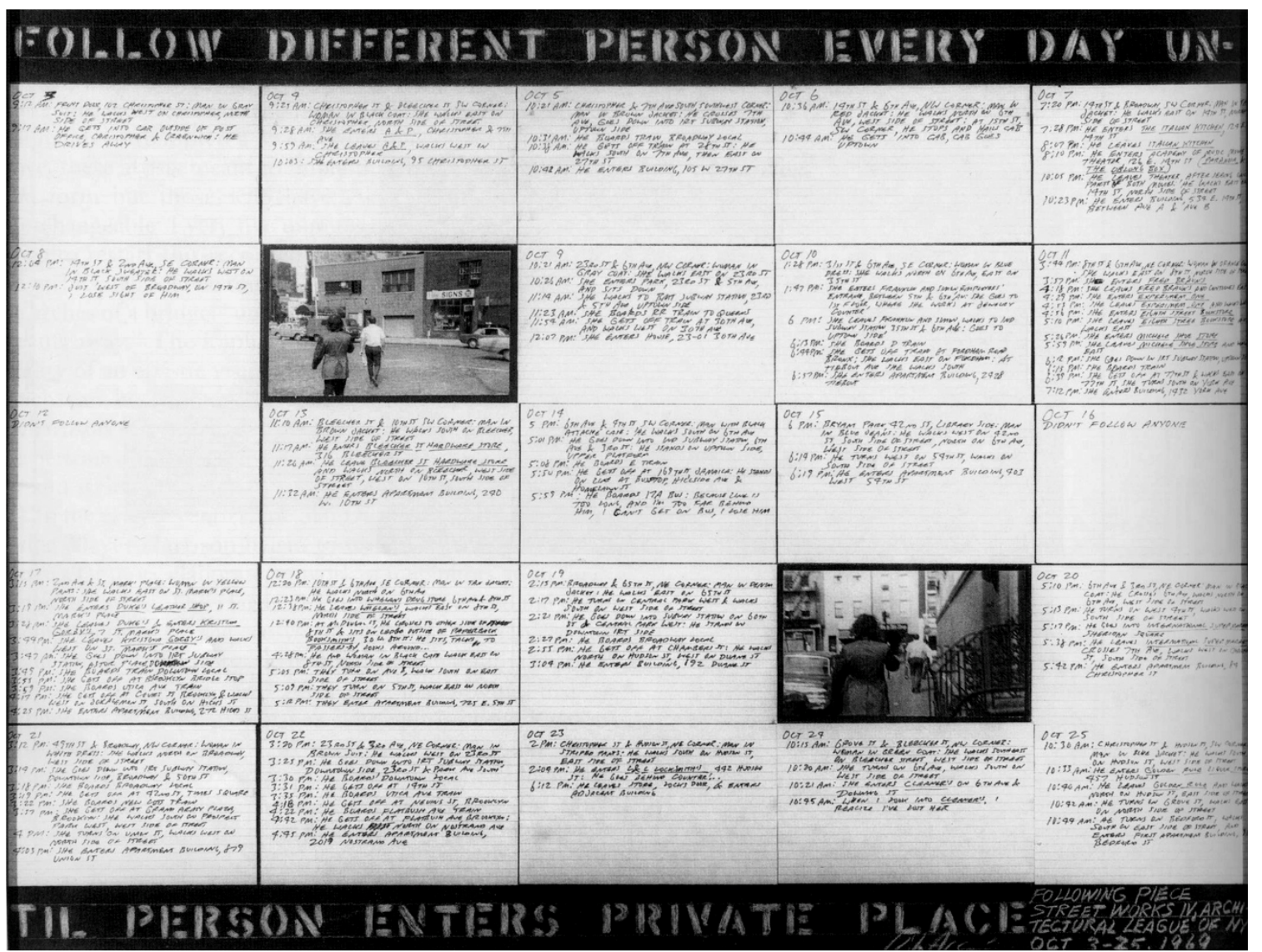

Figura 3. Vitto Acconci, Following piece. Performance realizada entre el 3 y el 25 de octubre de 1969.

Los seguimientos a desconocidos ya habían sido puestos en práctica en el ámbito artístico por Vitto Acconci en su acción Following piece, a los que daba fin cuando los perseguidos accedían a un espacio privado (figura 3). Mientras Vitto Acconci elegía al azar a sus perseguidos, Calle lo hacía en función de los lazos afectivos que iba generando sobre la marcha. Solía fijarse en hombres solitarios y anónimos que simplemente caminaban, y sus trabajos desprenden un alto grado de empatía con los personajes que escogía como sujetos de sus historias.

Para Calle, la ciudad es, como dice Benjamin, un "paisaje sin umbrales" (Benjamin 2004: 427). La Filature (1981) fue un trabajo que realizó cuando el Centro Pompidou de París le ofreció participar en la muestra colectiva Autorretratos. Calle se encontró en una encrucijada, ya que ello suponía convertirse ella misma en el objeto de observación. Finalmente, decidió invertir los papeles y contrató a través de su madre a un detective para que registrara sus pasos durante un día. Mientras el detective la seguía, la artista tomó nota de sus propias acciones y confrontó sus apuntes con las fotografías y las notas que el detective había tomado discretamente. De esta manera, un mismo trazado aparecía descrito desde dos puntos de 
vista: desde dentro a través de los sentimientos de quien lo realizaba, y desde fuera por medio de un lenguaje frío y distante propio del observador. Veinte años más tarde, Sophie Calle quiso conmemorar esta acción y se hizo seguir de nuevo por un detective en Vingt ans après, París (2001) (figuras 4 y 5).
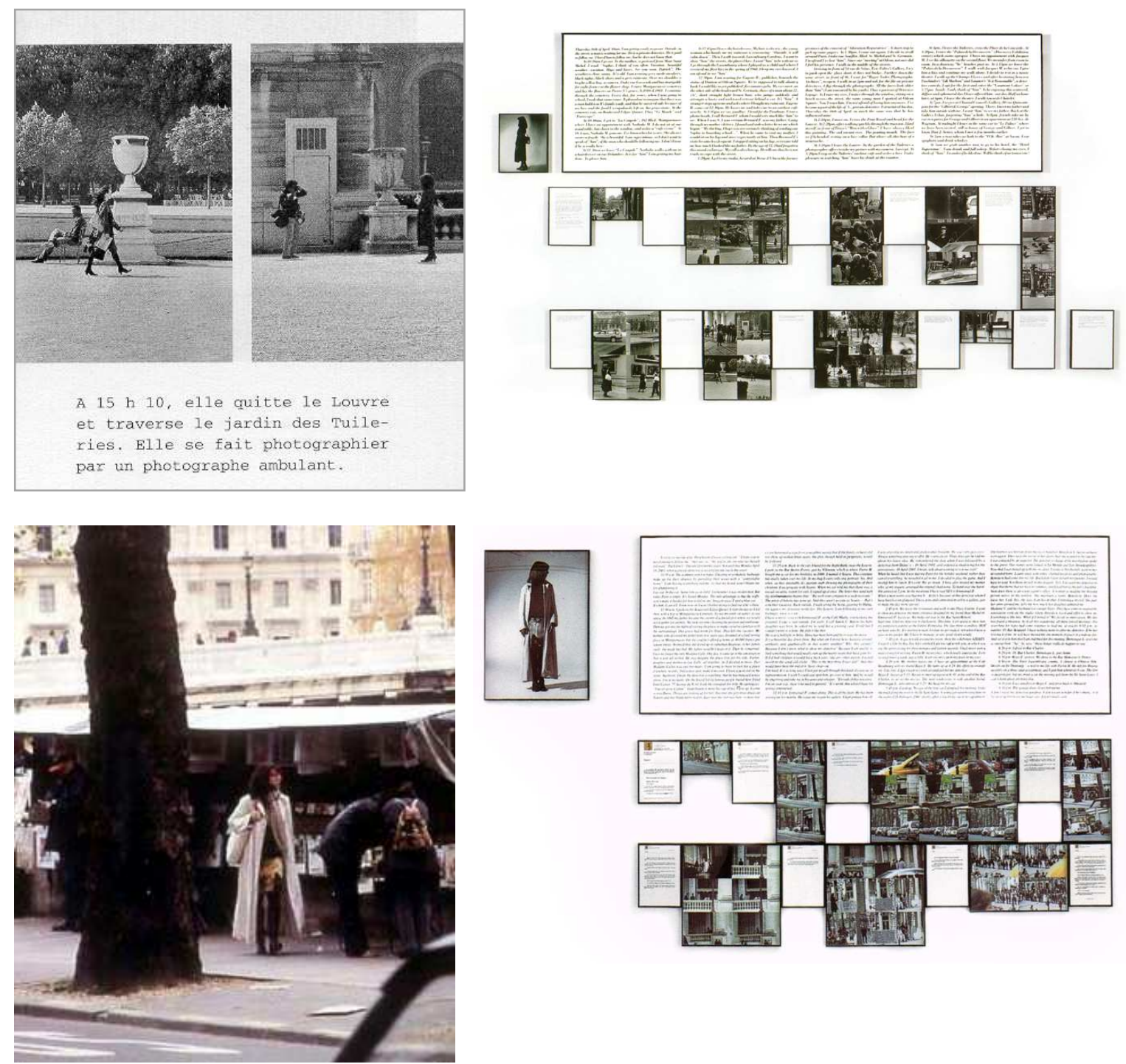

Figuras 4 y 5. Arriba: La Filature, 1981. Abajo: Vingt ans après, París, 2001.

\section{Nuevos enfoques}

Las nuevas tecnologías en la vida del ciudadano han facilitado el sedentarismo al mismo tiempo que han sido una herramienta para inducir el movimiento en la lectura de una narración y la observación de imágenes, que se presentan como ilustraciones. Los artistas desarrollan aplicaciones para dispositivos móviles con una narrativa que debe ser experimentada al mismo tiempo que se camina por la ciudad. El recorrido evoca un hecho histórico o cotidiano subjetivo, según la propia experiencia del caminante. Se están desarrollando 
numerosas aplicaciones en las que el artista propone una historia, real o imaginada, propia o apropiada, emulando las primeras situaciones y evocaciones descritas en los años 60.

Una herramienta utilizada, desarrollada por escoitar.org, es la plataforma noTours para teléfono Android, que se conecta a satélites GPS disponibles. Su editor se basa en la web, con el fin de que puedan añadirse los puntos en el mapa desde un ordenador conectado a internet. A cada punto se asocia un sonido o narración, de tal manera que para escucharlo hay estar físicamente en el lugar, es decir, es necesario realizar el recorrido del camino trazado previamente. Serendipia, de Helena Torres, es una narrativa sonora geolocalizada llevada a cabo en el cementerio civil El Sucu de Ceares (Gijón) y plantea la resolución de un crimen (Torres 2011). Dentro del género policial, se incita a la reflexión sobre historias personales y las que forman parte de la Historia, mediante un recorrido por el tiempo y el espacio. Los paseantes se sitúan en el clima político y social de finales del siglo XIX. Las huellas del pasado originan una reinterpretación de la figura de Rosario de Acuña, enterrada en este cementerio en 1923, primera mujer que leyó sus poemas en el Ateneo de Madrid, primera en defender su anticlericalismo desde una tribuna, y una de las pocas de su clase que se atrevió a amancebarse con el hombre con el que vivió hasta el final de sus días. Tuvo por tanto una vida muy parecida a la del pintor asturiano Edgardo del Pozo. A través de diferentes documentos surge la historia, parte real y parte ficticia, a la que se acerca el espectador mediante la escucha atenta de sonidos y la observación del espacio cargado de símbolos históricos.

Utilizando la misma plataforma, El tiempo re-velado (Lapeña Gallego 2013) trata diferentes aspectos históricos que han desembocado en la discriminación de la mujer en el ámbito público. A través de huellas escondidas en la ciudad se ponen en evidencia situaciones que estimulan en el espectador un proceso reflexivo y subjetivo, posible por el poder de la imagen y la narrativa sutil. Se desarrolla en el casco histórico de Murcia, y se debe recorrer siguiendo el hilo de una serie de microrrelatos que pueden ser escuchados si se capta su código QR. Cada código nos remite a la entrada correspondiente de un blog de acceso público creado para subir los vídeos. La opción comentarios permanece activada para permitir a los usuarios dejar sus opiniones acerca del proyecto, dándole un carácter participativo.

La literatura electrónica ligada a lugares específicos o recursos locativos e hipertextos ofrece grandes posibilidades de investigación, potenciada por el desarrollo de dispositivos GPS, móviles y tabletas. Podemos citar tres ejemplos: Dark London (Museum of London 2012), una novela gráfica interactiva basada en los personajes de Dickens e ilustrada por David Foldvari, que puede descargarse para iPad y iPhone, combina 
mapas, fotos, ilustraciones, archivos de texto y audio, como puede leerse en la página del Museo de Londres. Las distintas ediciones se podrán ir descargando desde iTunes y van acompañadas de audio para dar voz al propio Dickens. El lector pasea por las calles de Londres, pero las historias tienen ya una secuencia predeterminada por la novela a la que hace referencia.

Dentro del listado que nos ofrece la página http://www.eastgate.com/locative/ sobre obras que utilizan el hipertexto, Itinerant (Rueb 2012) invita a dar un paseo por Boston Common y los barrios cercanos y a experimentar los sonidos del cuento clásico Frankenstein (1816) de Mary Shelley, como se muestra en la página de Locative Hypertext. El texto original de la obra que suena es recogido y reinterpretado por los visitantes que pasean por la ciudad. Se incita así a la reflexión sobre el mundo móvil, la sociedad saturada tecnológicamente y la identidad del lugar y el desplazamiento.

Por último, Gabriela Infinita (Rodríguez 2011) que fija un recorrido dirigido por un mapa y comienza en un lugar concreto, un jardín público, para continuar por el centro de la ciudad, pudiéndose salir del recorrido por diferentes caminos. La ruta se muestra en la publicación de la página oficial de la Universidad Pontificia Javeriana de Bogotá.

En el arte sonoro algunos proyectos artísticos en el espacio público convierten al andante por la ciudad en el autor de la obra. Lalya Gaye (Colectivo Dånk, Göteborg, Suecia) desarrolla proyectos multidisciplinares en la convergencia de arte, tecnología y diseño. En Sonic City (Gaye 20022004) la gente crea un paisaje sonoro personal individualmente en tiempo real. Los recorridos a través de contextos cambiantes se convierten en composiciones musicales. El paseante forma un dueto con la ciudad y todas las actividades cotidianas se convierten en música de una manera personal e individual.

\section{Conclusión}

Se ha reflexionado y escrito mucho acerca de cómo las ciudades han dejado de ser un lugar estable para convertirse en espacios en los que la movilidad y el tránsito son dos de sus rasgos más significativos. La mayoría de nosotros inicia su trayecto diario de manera automática, lo concebimos como el medio para llegar a un destino. Salimos a la calle a comprar. Los centros comerciales, nolugares que se han convertido en el punto de reunión y socialización. La ciudad es el escenario donde tienen lugar los acontecimientos imperceptibles, pero que encierran una fuerza poética. Moverse a pie y sin seguir el trazado ideado por el urbanista supone escapar de la normalización y control de la ciudad. Es por ello que adquieren un perfil subversivo que denuncia el conformismo, la estabilidad y la inclinación sedentaria de la sociedad de consumo. 
Esta doble faceta de la ciudad, espacio y recuerdo, ha sido utilizada por artistas, que se alejan de la exposición en el cubo blanco para situarse en la calle. El recorrido horizontal o físico de desplazamiento se funde con el viaje vertical, evocador y poético, para constituir obras artísticas que, en esencia, comparten el hecho de caminar, y estéticamente vienen a ser consecuencia de las herramientas/técnicas del contexto en el que se ubica el artista.

\section{Bibliografía}

AGAMBEN, Giorgio (2007): La potencia del pensamiento. Buenos Aires: Adriana Hidalgo.

AUSTER, Paul (1992): Leviatán. Barcelona: Anagrama.

BENJAMIN, Walter (1970): Sobre el lenguaje en general y sobre el lenguaje de los hombres. Barcelona: La Gaya Ciencia.

- (1992): Cuadros de un pensamiento. Buenos Aires: Imago Mundi.

- (2004): El libro de los pasajes. Edición española de Rolf Tiedemann. Madrid: Akal.

BERGSON, Henri (1959): Materia y memoria. México: Aguilar.

CARERI, Francesco (2002): Walkscapes: el andar como práctica estética. Barcelona: Gustavo Gili.

CHOMBART DE LAUWE, Paul-Henry (1965): "Paris et I'agglomération parisienne", en Paris: Essais de sociologie, 1952-1964. París: Editions Ouvrières.

CRUZ, Manuel (2007): Cómo hacer cosas con recuerdos. Sobre la utilidad de la memoria y la conveniencia de rendir cuentas. Madrid: Katz Editores.

DE DIEGO, Estrella (2008): Contra el mapa. Madrid: Ediciones Siruela.

DEREN, Martina (2010): "Los rostros olvidados: Sophie Calle o la flâneuse contemporánea". Revista Acento, vol. 13, pp. 18- 25.

GARCÍA, Xosé Luis; y RUBIO, Olivia María (2010): "Itinerario por lo humano", en En Ars Itineris. El viaje en el arte contemporáneo (catálogo), pp. 8-11. Madrid: Ministerio de Cultura / SEACEX.

GAWOLL, Hans-Jürgen (1994): "El paseo (Ensayo sobre la anticuada usanza del andar)". Revista de Occidente, núm. 160, pp. 83-100.

GAYE, Lalya (2002-2004): "Sonic City" [en línea], en Lalyagaye.com. En: http://lalyagaye.com/sonic-city/ [Consulta: 12/03/2014].

HALBWACHS, Maurice (1968): La mémoire collective. Paris: Presses Universitaires de France.

LAPEÑA GALLEGO, Gloria (2013): "El tiempo re-velado". Arte y Políticas de Identidad, vol. 7, pp. 243-253.

LÓPEZ RODRÍGUEZ, Silvia (2005): Orientación y desorientación en la ciudad: La teoría de la deriva. Indagación en las metodologías de evaluación de la ciudad desde un enfoque estético-artístico. Tesis doctoral, Universidad de Granada.

MAROT, Sébastien (2006): Suburbanismo y el arte de la memoria. Barcelona: Gustavo Gili. 
MUSEUM OF LONDON (2012): Dickens. Dark London [en línea]. En: http://www.museumoflondon.org.uk/Resources/app/Dickens webpag e/index.html [Consulta: 12/03/2014].

OBERTI, Alejandra; y PITTALUGA, Roberto (2006): Memorias en montaje. Escrituras de la militancia y pensamientos sobre la historia. Argentina: Ediciones El cielo por asalto.

PINILLA BURGOS, Ricardo (2010): "Memoria y sensibilidad en Walter Benjamin". BAJO PALABRA. Revista de Filosofía, núm. 5, pp. 69-78.

RODRÍGUEZ, Jaime Alejandro (2011): "Gabriela Infinita" [en línea], en Universidad Pontificia Javeriana de Bogotá. En: http://www.javeriana.edu.co/relato digital/r digital/modelos/gabriell a.html [Consulta: 12/03/2014].

RUBIO REMIRO, Pilar (2011): "Caminar mejor que correr". Exit Express, vol. 57, pp. $15-21$.

RUEB, Teri (2012): Itinerant [en línea]. En: http://www.eastgate.com/locative/ [Consulta: 12/03/2014].

SÁNCHEZ RUIZ, Joaquín; y LÓPEZ-APARICIO, Isidro (2008): "La memoria: una estructura para la creación". Arte, Individuo y Sociedad, vol. 20, pp. 21-42.

SMITHSON, Robert (2006): Un recorrido por los monumentos de Passaic. New Jersey. Barcelona: Gustavo Gili.

TORRES, Helena (2011): "Serendipia" [en línea], en Narrativas espaciales: relatos sonoros geolocalizados. En: http://narrativasespaciales.wordpress.com/serendipia/ [Consulta: 12/03/2014]. 